\title{
Protracted neonatal hypertrypsinogenaemia, normal sweat chloride, and cystic fibrosis
}

\author{
C Castellani, A Tamanini, G Mastella
}

\begin{abstract}
The cystic fibrosis (CF) clinical spectrum has greatly expanded in the past few years, including atypical forms with low sweat chloride concentrations. Two cases are presented which suggest that children detected by neonatal CF screening whose trypsinogen concentrations are still raised by the second month of age could, despite a negative sweat test, be affected by an atypical CF with fully expressed pulmonary involvement.

(Arch Dis Child 2000;82:481-482)
\end{abstract}

Keywords: atypical cystic fibrosis; neonatal screening; hypertrypsinogenaemia; sweat test

Cystic fibrosis (CF) neonatal screening has long been based on the immunoreactive trypsinogen (IRT) assay on dried blood spot. Increased IRT concentrations at birth are characteristic of newborns affected by $\mathrm{CF}^{1}{ }^{1}$ but can also be found in healthy infants; however, IRT values tend to remain raised for several months in babies with CF, whereas in false positives they usually return to normal within the first weeks of life. ${ }^{2}$ In the 1980 s, before the discovery of the CF gene, the screening specificity was usually improved by retesting IRT at about 1 month of age: only neonates whose trypsinogen was still raised progressed to a sweat test, which was then the only definite diagnostic tool for CF, while infants with normal sweat electrolytes were dismissed as non-affected. However, in recent years, a growing number of atypical CF forms, including some with low sweat electrolytes concentrations, have been detected. ${ }^{3}$ We describe two cases which suggest that a negative sweat test is not sufficient to exclude CF in screened infants with persistently raised trypsinogen.

\section{Case reports}

The first patient is a 14 year old boy, referred to our centre in order to evaluate an exercise induced asthma poorly responsive to treatment. He had a history of persistent neonatal hypertrypsinogenaemia: his IRT (CIS Sorin RIA method) at birth was $93 \mu \mathrm{g} / 1$ (99.8 centile $=85 \mu \mathrm{g} / \mathrm{l})$ and continued to be raised, although gradually decreasing, at 1,2 , and 4 months (61, 57 , and $47 \mu \mathrm{g} / 1 \mathrm{respectively;} \mathrm{retesting} \mathrm{cut} \mathrm{off}$ value at one month $40 \mu \mathrm{g} / \mathrm{l})$. A diagnosis of CF was initially ruled out on the grounds of normal determinations of sweat electrolytes by the classic Gibson and Cooke pilocarpine iontophoresis method ${ }^{4}$ (weight 115 and $233 \mathrm{mg}$; $\mathrm{Cl}^{-} 18$ and $12 ; \mathrm{Na}^{+} 11$ and $7 \mathrm{mEq} / \mathrm{l}$; age at testing 2 months), and no clinical evidence consistent with CF. From 1 year of age he occasionally suffered from wheezing; at 4 he was found to be allergic to dust mites and wheat. Following a complex treatment including immunotherapy, inhaled bronchodilators, and steroids, the asthma episodes became less frequent, but bronchoconstriction following exercise persisted. From the age of 11 he started complaining of chronic productive cough. At 14 his weight was $39 \mathrm{~kg}$ (z score -1.09 ), and his height $152 \mathrm{~cm}$ (z score -0.86). Physical examination disclosed no disease signs but a spirometry test revealed a forced expiratory volume in one second $\left(\mathrm{FEV}_{1}\right)$ of 1.461 ( $57 \%$ of the predicted value), not responsive to salbutamol. Pseudomonas aeruginosa and Staphylococcus aureus were cultured in sputum, and bilateral nasal polyps and bronchiectases were detected. A pancreatic stimulation test showed normal duodenal outputs of bicarbonate, lipase, amylase, trypsin, and chymotrypsin, according to the reference values of our laboratory. ${ }^{5}$ Following these results a sweat test was repeated, and again it was negative (weight 201 and $151 \mathrm{mg} ; \mathrm{Cl}^{-} 26$ and $27 ; \mathrm{Na}^{+} 32$ and 34 $\mathrm{mEq} / \mathrm{l}$; age at testing 14 years). However, after a wide gene search with denaturing gradient gel electrophoresis analysis, two CF mutations were detected, R553X and D1152H. The conclusive evidence was provided by nasal potential difference (NPD) measurements, which showed a basal value of $-31.7 \mathrm{mV}$, and defective chloride secretion when the nasal mucosa was superinfused with a chloride free solution containing isoproterenol $(-1.7 \mathrm{mV})$. In our experience $^{6}$ both these results are consistent with a diagnosis of CF.

The second patient's history was similar. $\mathrm{He}$ had hypertrypsinogenaemia at birth $(102 \mu \mathrm{g} / \mathrm{l})$ and, to a lesser extent, at 1 and 2 months (64 and $62 \mu \mathrm{g} / 1)$; the sweat test was repeatedly negative (weight 163, 179, and $205 \mathrm{mg} ; \mathrm{Cl}^{-} 37$, 20 , and $20 ; \mathrm{Na}^{+} 34,23$, and $23 \mathrm{mEq} / 1$; age at testing 2 and 6 months). At 4 months a pancreatic stimulation test showed an output of bicarbonate and chymotrypsin below the 5th centile of the distribution in healthy subjects, while trypsin, lipase, and amylase outputs were within the normal range. ${ }^{5}$ As he was thriving and showed no symptoms compatible with CF, no further investigations were conducted until he was 12 , when, following a four year history of chronic productive cough and failure to thrive, he was again examined at our centre. His weight was $34.2 \mathrm{~kg}$ ( $\mathrm{z}$ score -1.06), his height $152 \mathrm{~cm}$ (z score 0.01). $\mathrm{FEV}_{1}$ was 1.051 ( $42 \%$ of predicted value), $S$ aureus was present in sputum, and he had sinusitis and bilateral bronchiectases. The sweat test was raised to 
borderline values (weight 213 and $209 \mathrm{mg} ; \mathrm{Cl}^{-}$ 44 and $51 ; \mathrm{Na}^{+} 43$ and $50 \mathrm{mEq} / 1$; age at testing 12 years), NPD basal value was $-30 \mathrm{mV}$, and genetic analysis showed a compound heterozygosity for $\Delta \mathrm{F} 508$ and $3849+10 \mathrm{KbC} \rightarrow \mathrm{T}$, the latter mutation usually being associated with CF with normal or borderline sweat chloride and pancreatic sufficiency. ${ }^{7}$ The patient is now 15, and colonised by $P$ aeruginosa.

\section{Discussion}

Non-CF hypertrypsinaemia has been reported in perinatal asphyxia and in some congenital pathological conditions, ${ }^{89}$ but in most cases the reasons for abnormal IRT values in infants without CF have not been established. The finding that some IRT positive heterozygous newborns with normal sweat chloride also carry another, mild CF mutation, has led to speculation that in some babies at least, raised IRT could be a phenotypic expression of an undetected compound heterozygosity, despite the low sweat electrolytes. ${ }^{10}$ In fact, the ability to detect CF mutations and to measure NPD has greatly expanded the CF clinical spectrum, which now includes atypical phenotypes with chronic sinopulmonary disease, pancreatic sufficiency, and normal sweat chloride concentrations. $^{3}$

These cases suggest that, despite a normal sweat test and the absence of clinical evidence in the first months of age, some infants with protracted hypertrypsinogenaemia can be affected by CF. Even though the normal sweat electrolytes are consistent with an atypical form of the disease, this does not imply mild clinical manifestations: in fact, the respiratory pheno- type was fully expressed in these two patients, who both had bronchiectases and chronic $P$ aeruginosa infection. Subjects with CF compatible symptoms and a history of protracted hypertrypsinogenaemia should be carefully evaluated for CF, even when their sweat test is normal. A retrospective assessment of children screened for CF who showed persistently raised IRT but were not examined by genetic analysis or NPD may be advisable.

We are indebted to U Pradal and A Delmarco from the Verona CF Center for NPD measurements, and to PF Pignatti and MG Benetazzo from the University of Verona Institute of Biology and Genetics for DGGE analysis. This study was partly supported by a grant from the Italian Ministry of Public Health (law 548/93).

1 Crossley JR, Elliott RB, Smith PA. Dried-blood spot screening for cystic fibrosis in the newborn. Lancet 1979;i:472-4.

2 Wilcken B, Brown ARB, Urwin R, Brown DA. Cystic fibrosis screening by dried blood spot trypsin assay: results in 75,000 newborn infants. F Pediatr 1983;102:383-7.

3 Rosenstein BJ, Cutting GR, Cystic Fibrosis Foundation Consensus Panel. The diagnosis of cystic fibrosis: a consensus statement. F Pediatr 1998;132:589-95.

4 Gibson LE, Cooke RE. A test for concentration of electrolytes in sweat in cystic fibrosis of the pancreas utilizing pylocarpine by iontophoresis. Pediatrics 1959;23:544-9.

5 Cipolli M, D’Orazio C, Delmarco A, Marchesini C, Miano A, Mastella G. Shwachman's syndrome: pathomorphosis A, Mastella G. Shwachman's syndrome: pathomorphosis and long-term

6 Pradal U, Castellani C, Delmarco A, Mastella G. Nasal potential difference in congenital absence of the vas deferens. Am F Respir Crit Care Med 1998;158:896-901.

7 Augarten A, Kerem B-S, Yahav Y, et al. Mild cystic fibrosis and normal or borderline sweat test in patients with the $3849+10 \mathrm{KbC} \rightarrow \mathrm{T}$ mutation. Lancet 1993;342:25-6.

8 Rock MJ, Mischler EH, Farrell PM, Bruns WT, Hassemer DJ, Laessig RH. Immunoreactive trypsinogen screening for cystic fibrosis: characterization of infants with a falsepositive screening test. Pediatr Pulmonol 1989;6:42-8.

9 Pederzini F, Armani P, Faraguna D, et al. Non-CF neonatal hypertrypsinemia. Insights into Pediatrics 1987;1:19-20.

10 Castellani C, Benetazzo MG, Bonizzato A, Pignatti PF, Mastella G. Cystic fibrosis mutations in heterozygous newborns with hypertrypsinemia and low sweat chloride. Am $\mathcal{F}$ Hum Genet 1999;64:303-4. 